This item was submitted to Loughborough's Research Repository by the author.

Items in Figshare are protected by copyright, with all rights reserved, unless otherwise indicated.

\title{
Systematising multidisciplinary sustainable building design processes utilising BIM
}

PLEASE CITE THE PUBLISHED VERSION

https://doi.org/10.1108/BEPAM-05-2020-0088

PUBLISHER

Emerald

VERSION

AM (Accepted Manuscript)

\section{PUBLISHER STATEMENT}

This paper was accepted for publication in the journal Built Environment Project and Asset Management and the definitive published version is available at https://doi.org/10.1108/BEPAM-05-2020-0088

\section{LICENCE}

CC BY-NC 4.0

\section{REPOSITORY RECORD}

Zanni, Mariangela, Kirti Ruikar, and Robby Soetanto. 2020. "Systematising Multidisciplinary Sustainable Building Design Processes Utilising BIM". Loughborough University. https://hdl.handle.net/2134/12801116.v1. 


\title{
Systematising Multidisciplinary Sustainable Building Design Processes Utilising BIM
}

\author{
Mariangela Zanni ${ }^{1 *}$, Kirti Ruikar ${ }^{2}$, Robby Soetanto $^{2}$ \\ ${ }^{1}$ School of Engineering and the Environment, Kingston University, London, UK \\ ${ }^{2}$ School of Architecture, Building, and Civil Engineering, Loughborough University, Loughborough, UK \\ *Email: mariangelazanni@gmail.com
}

\begin{abstract}
Purpose - Sustainability considerations are often treated as an add-on to building design, following ad-hoc processes for their implementation. The purpose of this study was to investigate, model, and facilitate the early stages of Building Information Modelling (BIM) enabled Sustainable Building Design (SBD) by formalising the ad-hoc working relationships of the best practices in order to standardise the optimal collaboration workflows.
\end{abstract}

Design/methodology/approach - Four stages of data collection were conducted, including a total of 32 semistructured interviews with industry experts from 17 organisations. Fourteen "best practice" case studies were identified, and roles and responsibilities, resources, information exchanges, interdependencies, timing and sequence of events, and critical decisions were examined.

Findings - The research classified the critical components of SBD into a framework utilising content and thematic analyses. These components were coordinated explicitly into a systematic process, which followed Concurrent Engineering (CE) principles utilising Integrated DEFinition (IDEF) 3 structured diagramming technique. Then, Green BIM Box (GBB) workflow management prototype tool was developed to analyse communication and delivery of BIM-enabled SBD in a centralised system.

Originality/value - This study represents an improvement to previous attempts to systematically define the BIM-enabled SBD process for the early stages. The results support the idea that a transparent SBD process, which follows specified communication patterns, can assist in achieving sustainability efficiently in terms of time, cost, and effort.

Keywords Sustainability, Design process, Building Information Modelling (BIM), Building Performance Analysis (BPA), Common Data Environment (CDE), Concurrent Engineering (CE), Integrated DEFinition methods (IDEF).

Paper type Research paper

\section{Introduction}

Sustainable performance of buildings is currently a major concern among AEC/O (Architecture, Engineering, Construction and Operation) professionals due to measures such as building legislations in addition to national 
and regional targets (HM Government, 2018; UK Green Building Council, 2019). To address this issue, many countries and international organisations have initiated rating systems (e.g. BREEAM, LEED, Passivhaus) to assess sustainable construction. Currently, these assessment methods are used as frameworks for environmental design by building professionals, although they provide little guidance over the design process. In addition, the design of such high performance buildings is a complex, non-linear, iterative and interactive process that requires effective collaboration between the multidisciplinary teams from the early stages in order to achieve sustainability outcomes (Bouchlaghem et al., 2005; Yang et al., 2013). As a consequence, Building Performance Analysis (BPA) workload becomes heavier at the early design stages compared to traditional project delivery. Furthermore, timely contributions of design participants and accuracy of the information delivered are important for Sustainable Building Design (SBD) to be successful (Brahme et al., 2001). For this reason, the most significant challenge to delivering a sustainable building is communication and co-ordination across a multidisciplinary team (Mills and Glass, 2009; Robichaud and Anantatmula, 2010). To date, the design process often suffers from lack of collaboration between design teams of different organisations. As a result, the most common problem to achieve a sustainable outcome is the absence of appropriate information to make critical decisions (DTI, 2007). Therefore, efficient and systematic information exchanges between designers, consultants and sub-contractors are essential to achieve design goals (Pala and Bouchlaghem, 2012). Crawley and Aho (1999) have described building design as a "top-down" process where the original concept is worked towards detailed design, allowing coordination between parties involved. In contrast, performance assessment follows the reverse route and is a "bottom-up" process where environmental performance is synthesised based on characteristics and technical details of the building elements (Zanni et $a l ., 2017)$. In SBD, the "bottom-up" processes should inform the "top-down" managerial process in order to achieve assurance for a holistic sustainable outcome.

What is more, despite the increasing adoption of Information Communication Technology (ICT), day-today communication often relies on basic media such as phone, email, and video conferencing. This fact undermines the importance of the contribution of certain disciplines at the early stages of design by making it ad-hoc despite being crucial for SBD. Appropriate use of ICT could facilitate integration of sustainability in the process, but it is likely to happen "only if the design managers employ a structured, systematic approach" (Pala and Bouchlaghem, 2012). This approach to information management would ensure that participants acquire the right information at the right time. Centralisation of information in an online Common Data Environment (CDE) (BSI, 2013b) would allow high level of coordination. For SBD, the need for coordinating a larger amount of information from a wider range of participants, as supported by CDEs, increases significantly (Bouchlaghem et al., 2005; Yang et al., 2013). Therefore, actors' roles within the multidisciplinary design team need to be re-defined to reflect the necessary relations between a number of diverse and interdependent tasks and activities. As the scale and scope of cooperative tasks is increasing, the shared level of responsibility for design aspects should be reflected in the use of collaborative systems, and thus, defined so as processes become more transparent and understood among the project's stakeholders. This study developed a process model for SBD, which can assist current industry practices to depart from ad-hoc 
collaboration workflows. The following Section frames the research problem and identifies the gaps in existing knowledge.

\section{Integration of sustainability considerations into building design processes}

Several construction industry reports have emphasised the importance of enhancing the quality of collaborative processes and that of the building design (Latham, 1994; Egan, 1998; Wolstenholme et al., 2009; Farmer, 2016). Despite the recent shift towards collective experiences of designers (Lloyd, 2017), most studies focus on the creative phenomena (i.e. cognitive processes) rather than organisational approaches. Although, integration of design strategies and disciplines is the recommendation of every design assessment tool (Green Building Education Services, 2011; BREEAM, 2014) and guide (Sinclair, 2013), there is still no systematic approach to guide collaborative SBD. The traditional building design process, such as the one described by the RIBA Plan of Work (RIBA, 2013), is a collection of discrete sequential tasks delegated to team members with little explicit demonstration over the interactions between them. RIBA (2013) considers sustainability aspects in a checklist and does not integrate them into the design process along with the core objectives. Previous attempts to integrate sustainability considerations into the building design process lack the element of sequencing of activities (Cinquemani and Prior, 2010; Bordens and Abbott, 2002; Reigeluth, 1999), and reasoning of decisions (Potts and Bruns, 1988; Lewis and Mistree, 1998). This problem is further exacerbated by the varying information needs of design disciplines (Brahme et al., 2001), which result in difficulties to make optimal design decisions. The Generic Design and Construction Process Protocol (GDCPP) is one of the first attempts to define the complete building design process in a comprehensive way (Kagioglou et al., 1998). The GDCPP model has not only described the physical stages of the process but has also addressed the management of design. However, SBD considerations are not included in the GDCPP. The BIM Project Execution Planning Guide, Version 2.2 (Messner, et al., 2019), has included considerations regarding energy consumption and LEED accreditation. Nevertheless, SBD is not considered in a holistic way, and the contributions of specialist consultants are overlooked.

Although BIM adoption, in the UK, has increased in recent years (RIBA Enterprises Ltd, 2019), there is scant evidence that sustainability is systematically considered as an integral part of the BIM collaborative process. Some BIM related frameworks are based on the international assessment rating systems (Wong and Fan, 2012; Ansah et al, 2019; Jalaei et al., 2020), while others have created tools that are integrated into BIM design software to automate performance based decision-making (Santos et al., 2020; Jaewook et. al., 2020; Schlueter and Thesseling, 2009; El-Diraby, 2017; Edwards et al., 2019). Recent approaches have also employed big data analytics to improve performance (Marzouk and Enaba, 2019). Nonetheless, organisational aspects of BIM-enabled SBD have not been addressed sufficiently in the literature despite the fact that any resources for technology implementations should be split (Wilkinson, 2005; Shelbourn et al., 2007): 40 per cent people, 40 per cent process, and 20 per cent technology. This fact is controversial since most current research on BIM has focused on technological issues instead of process and people ones. The biggest 
challenge that this incorporation faces is the lack of coordination among people, tools, deliverables, and information requirements (Succar et al., 2012; Ruikar et al., 2006).

A review of literature suggests a lack of a common definition for a BIM-enabled SBD process. SBD remains subject to interpretation, and ad-hoc processes are common. As each discipline works in isolated silos, the design outcome is compromised by failing to capture and integrate their inputs in a timely fashion. Clear definition of a multidisciplinary SBD process will assist practitioners to work collaboratively and add value to the design by harnessing the intellectual inputs of the various stakeholders. As the scale and scope of cooperative tasks is increasing, the shared level of responsibility for design aspects should be reflected in the use of collaborative systems, and thus, defined for processes to become more transparent and understood among the project's stakeholders. A well-defined and mapped methodology for multidisciplinary SBD can maximise the use of technological enablers (such as BIM, ICT, and BPA), for the early stages (concept design), so as to reap the benefits gained in the context of distributed teams that are the norm in construction (Bouchlaghem, 2012).

It is argued that a structured BIM-enabled collaborative design process can improve multidisciplinary communication, and thus, assist in achieving sustainability objectives more efficiently. The research attempts to identify lessons learnt from the best practices so that it can be used to inform the design of sustainable buildings in the future. It is intended to identify the components of SBD and develop a process model, which can assist industry practices to depart from ad-hoc towards defined collaboration workflows.

\section{Research design}

In order to meet the research objectives, this study adopted an abductive approach (iterative process of induction and deduction) (Dubois and Gadde, 2002; Levin-Rozalis, 2004; Reichertz, 2004; Svennevig, 2001). The implemented process was a reiteration of "testing" and "explanation" with continually checking the external validity of the research outputs (Meredith, 1993). The "iterative theory building process" (Drongelen, 2001) consisted of four stages of data collection and analysis (see Figure 1 and Table 1).

The scope of sampling evolved progressively in order to serve the needs of the research:

- Stage 1 (Exploratory stage): Theoretical sampling (Bowen, 2008; Glaser, 1978), while shaping the research hypothesis; theoretical frame, although selective, still not defined sufficiently to qualify for purposive sampling. Early decisions are based on general understanding of the researcher regarding the subject and problem area.

- Stage 2 (Main data collection stage): Criterion sampling (Coyne, 1997; Ritchie et al., 2013); serves to investigate in depth a particular type of case and identify all sources of variation.

- Stages 2 and 3 (Main data collection, and Validation stages): Snowball or chain sampling; locate one or two key individuals, and then, ask them to name other informants that also meet the criteria, when possible. Serves to facilitate the identification of hard-to-find cases that are inaccessible (Baker and Edwards, 2012; Davies and Dodd, 2002; Ritchie et al., 2013). 
- Stages 2 and 3 (Main data collection, and Validation stages): Stratified sampling, or purposive sampling, controlled by the researcher (Barbour, 2001; Coyne, 1997; Patton, 1990). Serves to illustrate characteristics of particular subgroups of interest and facilitate comparisons.

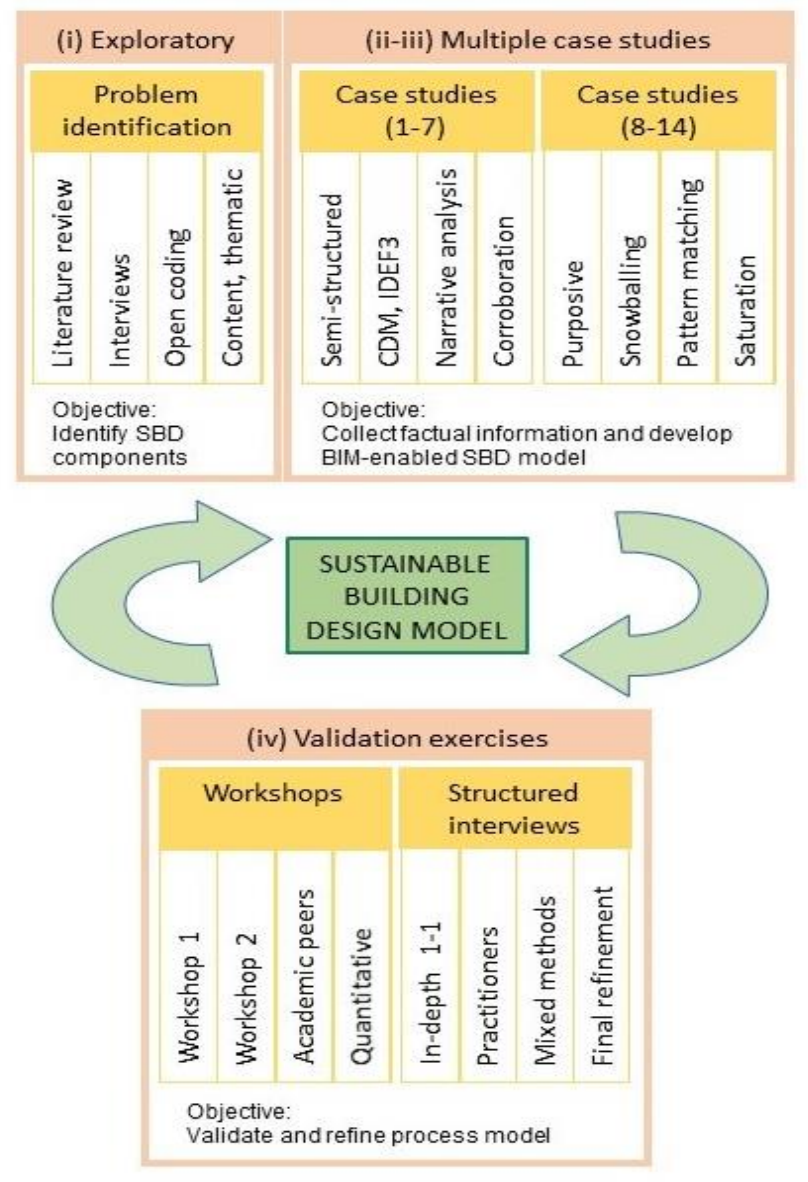

Figure 1: Research design overview

The best practices were defined as those which achieve high standards of environmental performance, and human comfort and health as well as business and commercial objectives (e.g. BREEAM Outstanding, Passivhaus certification, specific attention to embodied carbon and embodied energy of materials, minimised energy use and lifecycle carbon, maximised daylight, maximised natural ventilation, testing for robustness to climate change). Furthermore, the best practices help to realise a quality outcome within the set project programme and budget by following sustainable project delivery methods that avoid unnecessary re-work and delays. The participants were asked to identify examples of successful and unsuccessful collaboration workflows, based on the sustainability outcome. This process continued until no more information, related to the research questions, was provided by the experts (theoretical saturation/information redundancy). It served to: (i) identify and define the main elements of the process (i.e. roles, responsibilities, tasks, deliverables, and critical decision-making points); (ii) coordinate this into a holistic process by identifying interdependencies between them; and (iii) develop a mock-up of a prototype application of a workflow management system that facilitates the standardised process. 
Table 1 Summary of research stages, methods and techniques (4 stages)

\begin{tabular}{ll}
\hline Data collection stages \\
\hline i $\quad$ Exploratory research \\
Objective: To identify SBD components and \\
explore the constraints before launching the \\
main data collection. \\
Participants: 5 Architects. \\
Techniques: Literature review survey; \\
Theoretical sampling; Exploratory interviews. \\
Outputs: Voice recordings.
\end{tabular}

ii Multiple case studies (i.e. higher education, public library, museum, hospital, and 2 schools).

Objective: To collected factual and attitudinal information (qualitative and quantitative) of real-life incidents.

Participants: 4 Architects, 2 Passivhaus Consultants, 2 Sustainability Consultant, and 1 BIM Manager.

Data analysis stages

\section{Content and thematic analyses}

Objective: To develop initial high-level process model and gain better understanding of the research problem.

Techniques: Verbatim transcription; Open coding; Data tabulation.

Outputs: Research gaps identification; Improved research strategy and questions; High-level process decompositions.

\section{Narrative analysis}

Objective: To identify elements and patterns of the early stages of collaborative SBD.

Techniques: Verbatim transcription; Open coding; Data tabulation; Integrated DEFinition method (IDEF3); Corroboration.

Outputs: Flowcharts and detailed model decompositions; Development of theoretical framework; Identification of knowledge gaps.

Techniques: Criterion sampling and snowballing; Semi-structured interviews; Critical Decision Method (CDM).

Outputs: Voice recordings; Observational data; Case studies' documents.

iii Multiple case studies (i.e. shopping centre, higher education, and 4 offices).

Objective: To refine and complete the process model and framework.

Participants: 2 BIM Managers, 2 Mechanical Engineers, 1 Sustainability Consultant, 1 BREEAM Assessor, 3 Architects, 2 Sustainability Engineers.

Techniques: Criterion sampling and snowballing; Semi-structured interviews; CDM.

\section{Pattern matching}

Objective: To revise the detailed processes' decompositions.

Techniques: Verbatim transcription; Open coding; Data tabulation; Integrated DEFinition method (IDEF3); Corroboration.

Outputs: Completed theoretical framework of components; Completed structured holistic process model that establishes the relationships Outputs: Voice recordings; Observational data; Case studies' documents.

\section{iv Validation exercises}

Objective: To evaluate and refine the IDEF3 structured process model.

Participants: 8 Academics, 7 Industry experts. Techniques: Stratified/purposive sampling; 2 Workshops, and 7 Structured interviews.

Outputs: Voice recordings; Observational data; Completed questionnaires.

\section{Theory testing}

Objective: To assess the completeness, accuracy, and adequacy of the IDEF3 process model.

Techniques: Verbatim transcription; Data tabulation; Data charting; Minor revisions. Outputs: Final IDEF3 process model; Theoretical saturation; Quality assurance. 


\section{BIM-enabled SBD}

This section describes the coordination of the SBD components, and the development of detailed decompositions, utilising the Critical Decision Method (CDM) (Klein et al., 1989). It identifies the patterns that occur during collaborative design of sustainable buildings in order to develop a standardised model for the early stages of SBD based on lessons learnt (successes and failures) of the best practices. Then, it presents the development of a system's architecture for a workflow management tool for SBD process automation (Green BIM Box, GBB). GBB is a conceptual workflow management prototype tool that makes design goals, roles, responsibilities, methods, and deliverables explicit by systematising them into a common process based on the lessons learnt.

\section{Identification of SBD components (stage 1)}

The focus of this stage was to identify the key components and characteristics of BIM-enabled SBD (see Figure 2). It also resulted in identifying constraints in preparation for the main data collection stages (2-3). The findings suggest that a paradigm shift towards integrated multidisciplinary design processes can facilitate a more sustainable building outcome. The SBD process is information driven and its management is information related; social interaction, and technological enablers and barriers, facilitate or hinder the process accordingly. The roles, responsibilities, information exchanges, methods, tools, and their interdependencies need to be made explicit in order for the design process management optimisation to happen. A CE systematic approach can be utilised to standardise repeatable processes that lead to high-value collaborative SBD. Thus, the CE process model developed in this research strived to integrate sustainability considerations throughout the design process so as to make explicit the trade-off relationships between varying areas of expertise. For this reason, the tasks, deliverables, and critical decisions points were identified based on the workflows of the best practices for SBD. As a result, better team alignment is facilitated by using the existing technological enablers so as to move from a hierarchical structure towards a centralised system architecture. This approach would increase understanding of the implications of certain design decisions at the overall design outcome, and assist in preventing failures. 


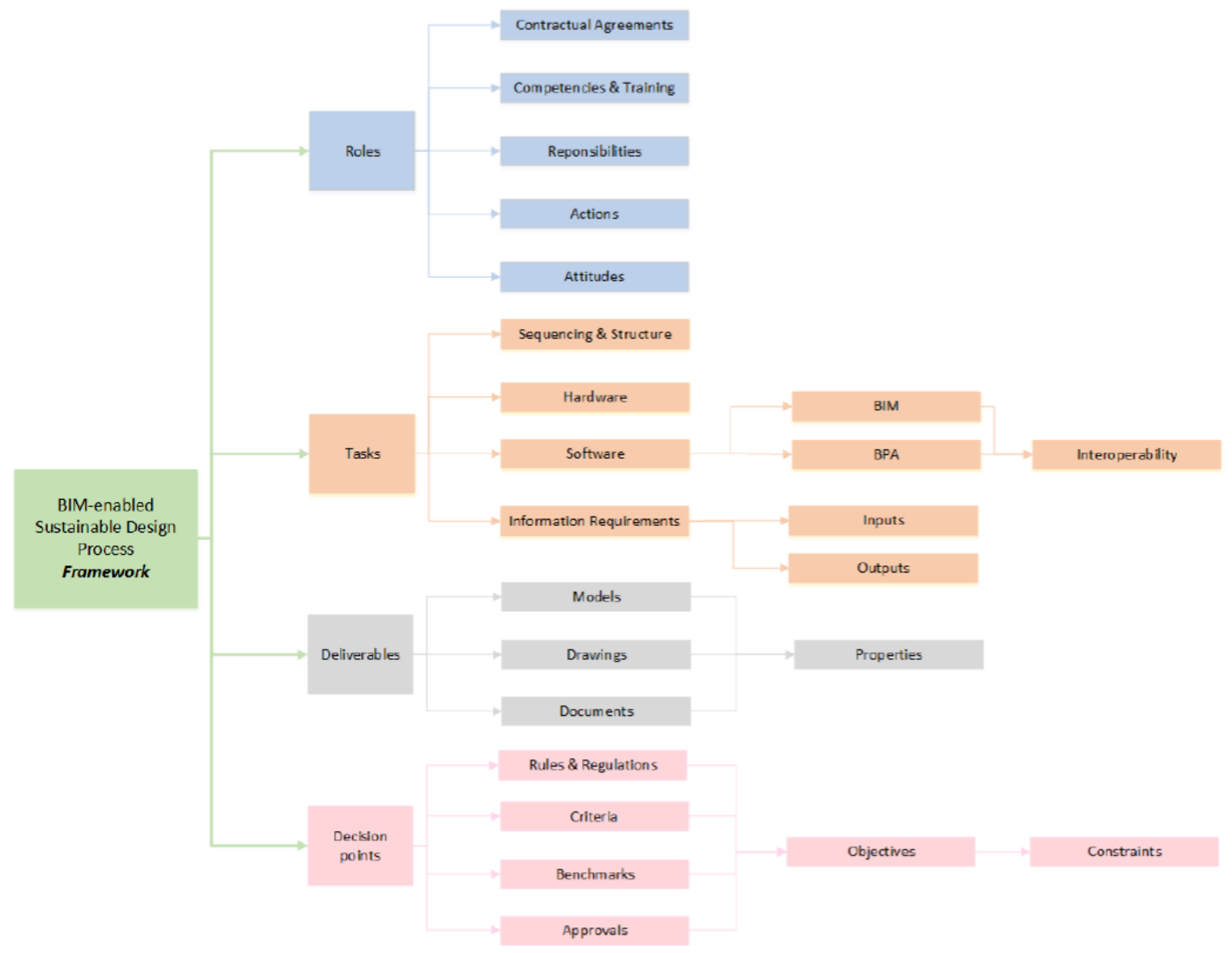

Figure 2 BIM-enabled SBD process components

IDEF3 process decompositions (stages 2-3)

This subsection discusses the development of the detailed decompositions for RIBA Stage 2 (Concept Design). It presents the Model/BIM Uses (i.e. tasks delegated to design roles), Model-based deliverables and information requirements, and coordinates them into a holistic process for SBD. The tasks, or Units of Behaviour (UOBs), that are included in the developed IDEF3 process model, are the BIM-enabled SBD uses, which are performed utilising BIM and BPA software, and a CDE. The interviews conducted during this research utilised the CDM to elicit the experts' knowledge so as to determine detailed-level IDEF3 processes and sub-processes (Mayer et al., 1995). CDM uses the "scenario" as the basic organising structure for establishing the focus and boundary conditions for the process description. The procedure to elicit scenarios was the following:

i. Selection of an incident that had a significant effect on the sustainability outcome of a certified sustainable non-domestic building that BIM software was utilised.

ii. Description of incidents was obtained in order to build context, understand unique perspective, activate memory, and achieve cooperation. Additional questions were asked regarding the sustainability objectives (both included in the brief and tacit ones), and the methods used. 
iii. Specification of the sequence of events that took place during the incident (including interactions with other project participants, artefacts, and content of information exchanges).

iv. Identification of decision points in the process, when different design options were considered (including alternative solutions).

v. Specification of goals (and assessment methods) at the time, along with the options for each decision (choices made or rejected). The basis for selecting an option was requested, and whether a rule was used. Additional constraints were also discussed.

vi. Reflection on the incident focused on the lessons learned from the experience and included suggestions about what should have been done to prevent the unwanted outcomes in order to achieve a more sustainable building.

Combined with the IDEF3 method, CDM allowed many scenarios and viewpoints to be amalgamated into a single diagram as it is tolerant of partial, or inconsistent, descriptions (Mayer, 1992). The Narratives served to identify the BIM-enabled SBD sub-processes' interdependencies, and the names of their functions whereas the IDEF3 diagrams present the sequencing and structure of the SBD process' workflows. As a result, the IDEF3 model illustrates the identified relationships between BIM-enabled SBD uses (as UOBs), the gateways and critical decision points (as Junctions), and the iterations' cycles of the SBD collaborative process. The Inputs (information required) and Outputs (information shared) of the functions are illustrated as Objects. The Objects' states (e.g. Initial, Optimised, Approved, Shared) change as they are altered by the functions.

Twenty Narratives served the purpose to validate, and enrich, the model by providing information from incidents based on the experts' experience. Below is an example of two Narratives along with their contribution to the IDEF3 process model's evolution (illustrated in Figure 3):

1. During the requirements definition (briefing), the Sustainability Consultant targets to find the comfort and climate mismatch for each season, and performs analysis to understand which passive design strategies are appropriate to mitigate the climate's impact examining parameters such as temperature ranges, solar availability, wind direction and intensity, and humidity. At Phase 1 (UOB 2.1) "building massing", an initial building mass is developed (UOB 2.1.1) by the Architect (LOD100 - Initial). Then, sensitivity studies are performed, by the Sustainability Engineer, to understand the heating and cooling loads (UOB 2.1.2) of each alteration of the building's form so as to reduce the energy consumption. Along with that, overshadowing studies are performed (UOB 2.1.3) to see how the building casts shadows on itself and on neighbouring buildings. The optimal orientation that reduces the heating and cooling loads is also examined (UOB 2.1.4). The result is the optimised Architectural BIM LOD100.

2. Another Interviewee described the sustainability assessment process of a commercial office building. In the first instance, the Sustainability Engineers received a massing model LOD100 (UOB 2.1.1). Then, they assessed overshadowing and access to daylight (UOB 2.1.3), thermal performance (UOB 
2.1.2) and photovoltaics' potential (i.e. solar analysis, UOB 2.1.5). Regulatory requirements and planning constraints were considered at this point before proceeding. For that reason, extensive engagement with the Planning Consultant was required (Junction J4). UOB 2.1 was amended accordingly (see Figure 3).

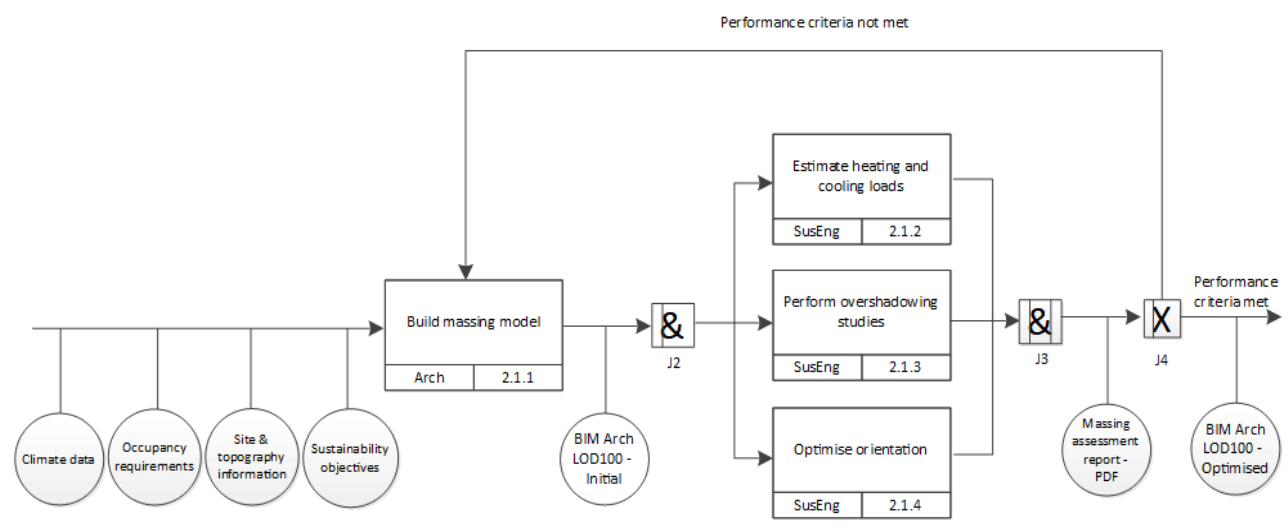

$1^{\text {st }}$ iteration

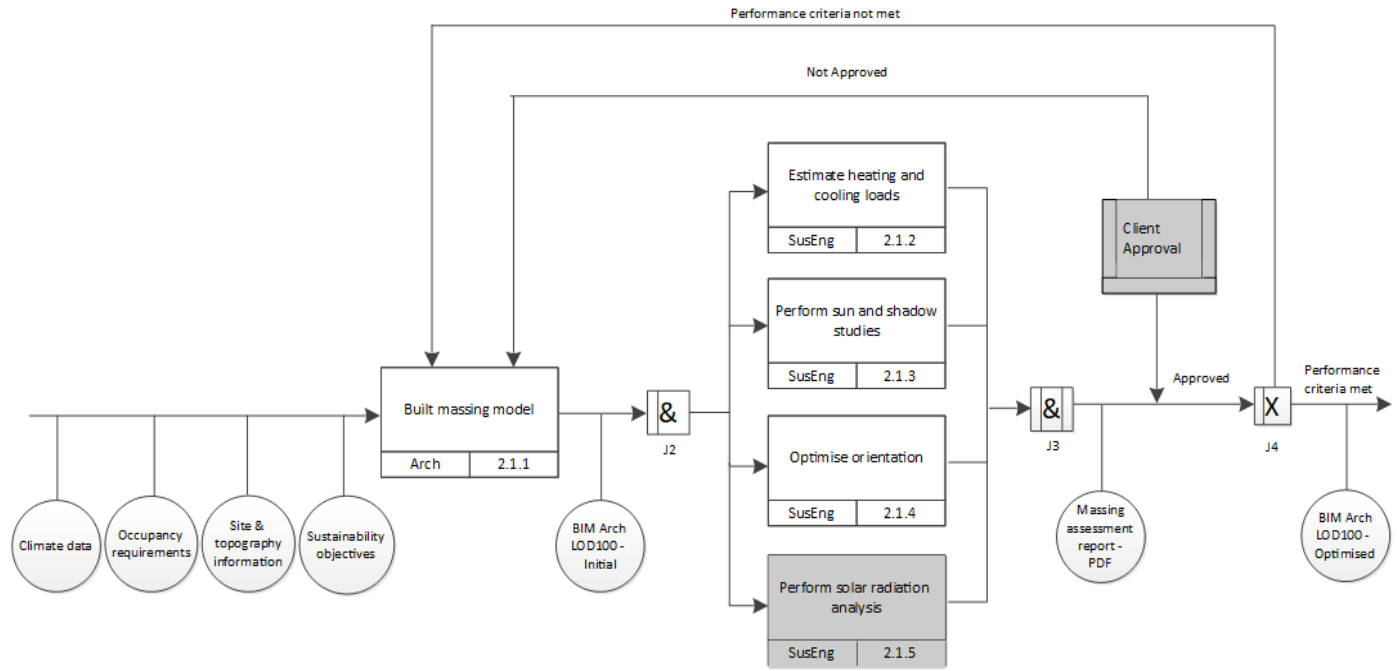

$2^{\text {nd }}$ iteration

Narrative 1
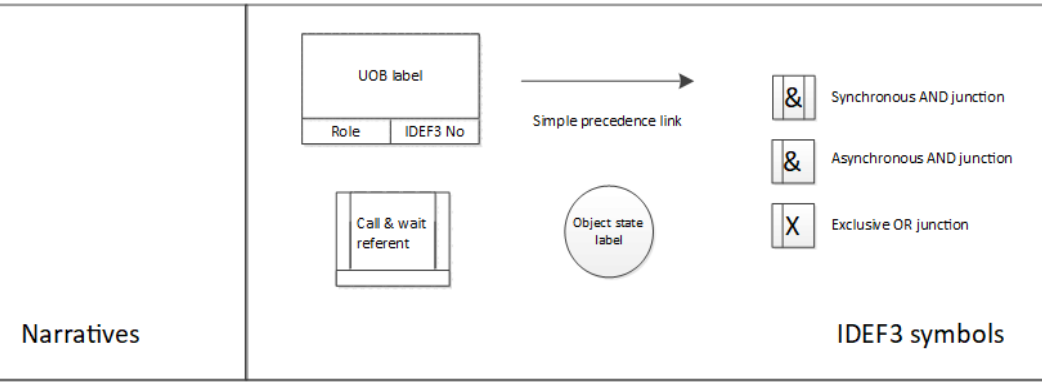

\& Synchronous AND junction
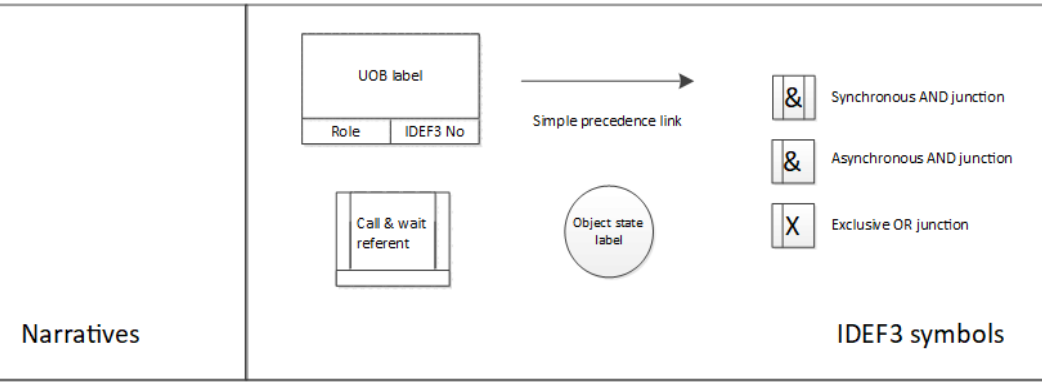

\& Asmchronous AND junction

Narrative 2

Figure 3 Evolution of "Building Massing" [UOB 2.1] 
GBB workflow management system (stages 2-3)

GBB is a prototype tool that formalises design goals, roles, responsibilities, methods, and deliverables coordinating them into a common process holistically based on the lessons learnt from the best practices. GBB aims to enable a shift from the traditional linear collaboration SBD process into a concurrent one, where the design is developed and assessed at the same time, during Work-In-Progress (WIP). Thus, it facilitates rulesbased coordination in a centralised information management system (i.e. CDE). This Section defines the ontology of the prototype application, developed in this research, so as to provide an understanding of its structure and schematics (Uschold and Gruninger, 1996).

GBB's three-layer system design (Buschmann et al., 1996; Microsoft, 2015) consists of: (i) the Presentation layer, (ii) the Service layer, and (iii) the Data and Knowledge Access layer (see Figure 4). The Presentation layer is the User Interface (UI) of the application, which is web-based utilising a web browser (e.g. Google Chrome). Furthermore, plug-in applications for discipline specific applications are considered (e.g. Revit, IES-VE) in order to facilitate the multiple perspectives that are required. The Service layer is located in a web server so as to coordinate the top and bottom layers by containing the logical decisions and the commands of the application. Its role also includes moving the processed data between them. In this scenario, the middle layer contains the IDEF3 process model with the workflows, which are the rules of the developed system. These functions include management, team support, access codes, system's rules, and data mapping. Query management, document management, approval, messaging, and quality management are its main functionalities (Wilkinson, 2005). The Data and Knowledge Access layer consists of one or more databases (e.g. CDE) where the Graphical (e.g. individual models, and federated model) and the Nongraphical information (e.g. documents, and specifications) are stored. Foundation services can be used by all three layers (Microsoft, 2015); those include Security and Communication (e.g. asynchronous messaging) layers. 


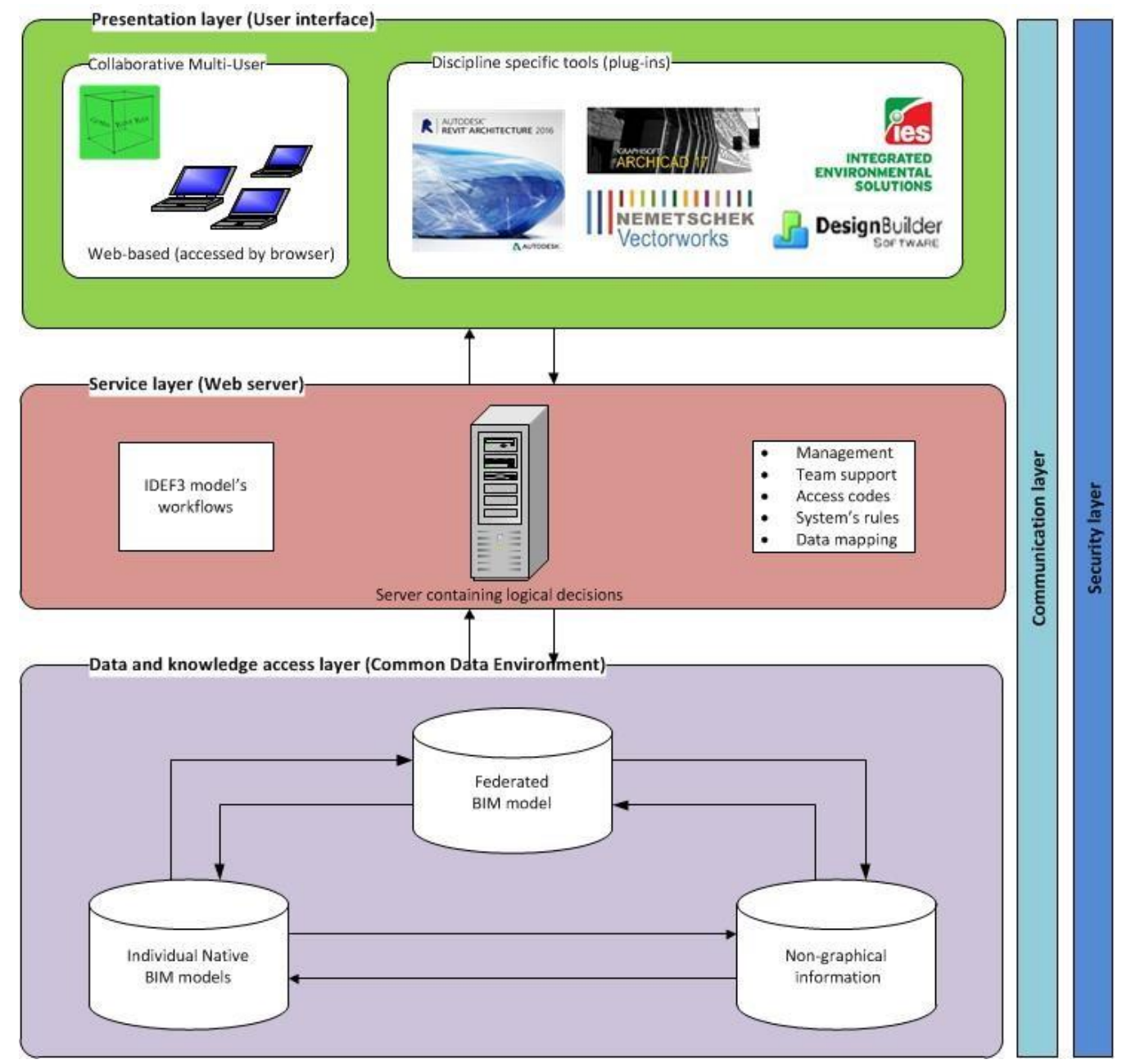

Figure 4 Green BIM Box three-layered system architecture

The description of the Use Case Scenario, shown in Figure 5, corresponds to UOB 2.1 "Develop building massing" of the IDEF3 process model (Figure 1). Once the Architect completes UOB 2.1.1 "Build massing model", they upload the BIM-Arch LOD100, either utilising the plug-in application, or through the web browser-based application. The system audits the task, prompts for correct naming according to BS EN ISO 19650-1:2018 (British Standards Institution, 2019), and counts (latest version ensured). The BIM file is stored in the Data and Knowledge Access layer and the Architect receives a confirmation that the process has been completed successfully. Then, the system automatically sends notifications to the stakeholders that have requested, and are authorized, to have an overview of the process (in this example, the Project Manager). Furthermore, the system prompts action from the Sustainability Engineer (to a set deadline). These asynchronous messages do not require immediate responses from the Receivers. Once the Sustainability Engineer, performs their assigned tasks (UOB 2.1.2 to 2.1.5), they upload the file/s (e.g. massing assessment report) to the system, following a similar process like the Architect (plug-in or web browser-based app). The system automatically notifies the stakeholders that have requested progress notifications (e.g. Project Manager) along with the ones that are required to take action (e.g. Client). Once the Client has reviewed the 
files, uploaded by the Architect and the Sustainability Engineer, they either Approve or Not Approve (accept or deny) the results, based on performance criteria or personal aesthetics. In case the outcomes of the tasks are Not Approved by the Client (or the responsible stakeholder), a loop is created, and the process iterates at the beginning. As soon as the outcomes are approved, all stakeholders that have participated in the process (Architect, Sustainability Engineer, and Project Manager) are notified that the task (UOB 2.1) is completed, and they are prompted to start the next assigned task (UOB 2.2). Following this approach, GBB assists in accelerating information exchange procedures, while keeping an audit trail of information delivered. Therefore, it can serve as a single source of truth for the project team in terms of version tracking, goal setting, and resolving of issues.

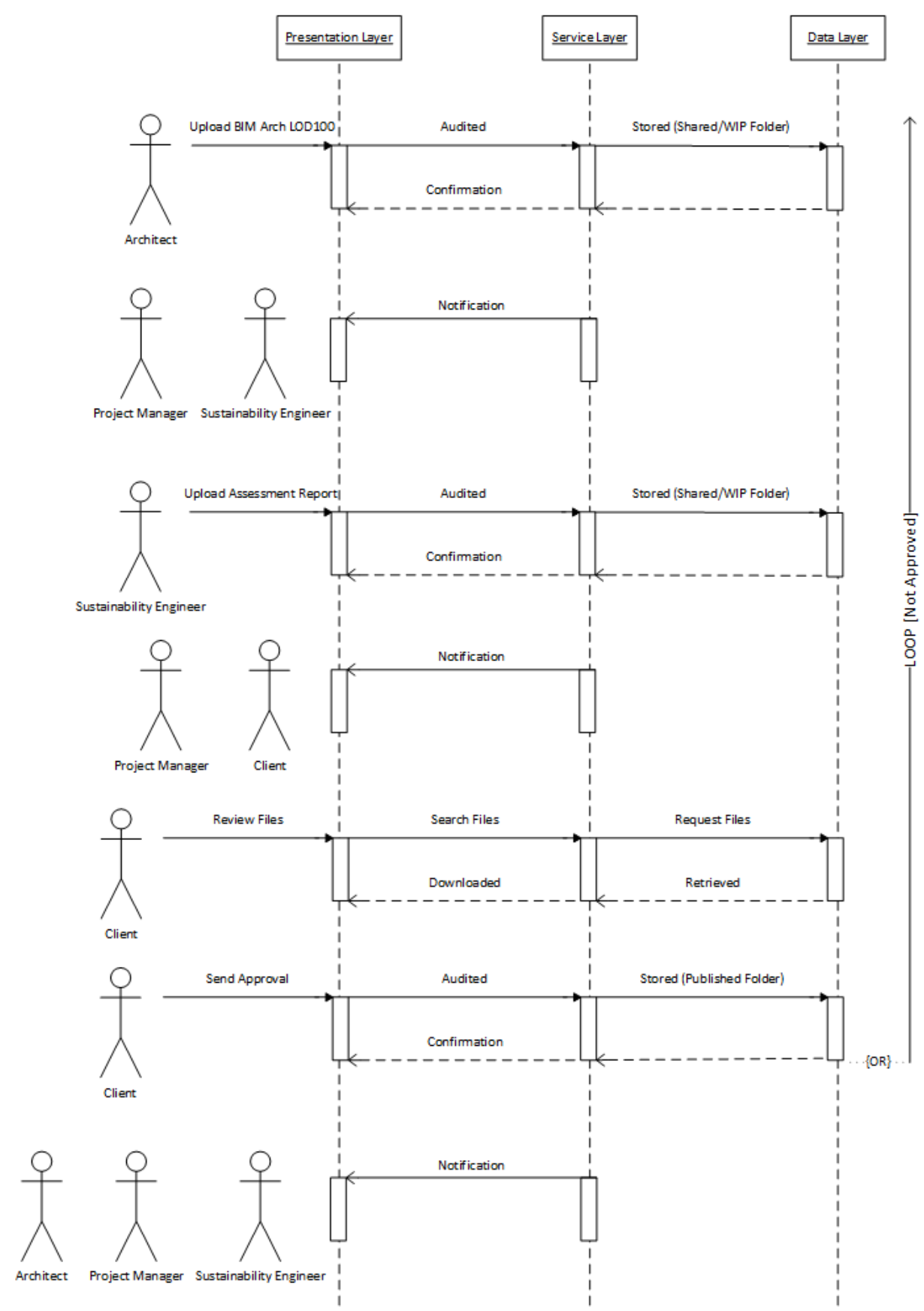

Figure 5 Use Case Scenario "Building Massing" [UOB 2.1] 


\section{Validation of the systematic process (stage 4)}

Two workshops with 8 academic peers (specialising in SBD) served as pilots before the interviews with 7 industry experts were conducted, as presented in Table 1 (stage 4). The sample consisted of varying areas of expertise (e.g. architectural design, BPA, and certification schemes). The industry participants were selected based on criteria of relevant practical experience, and the sample included both experts that participated during the main data collection (stages 2-3) as well as participants that had not been involved with the research project before. The participants examined the IDEF3 process model before the interviews took place; its description along with the questionnaire handouts were provided in advance. There was consensus, amongst the industry experts interviewed, regarding the usefulness and adequacy of the IDEF3 process model for the implementation of multidisciplinary SBD. The participants considered the research output to be very well-structured, clear, relevant, comprehensive, and easy to understand and navigate. Furthermore, they have acknowledged its value as a guideline for considering the most critical aspects of sustainability at concept design stage, and for communicating them among the design team for better alignment. Overall, the feedback was enthusiastic with the participants emphasising on the appropriateness of the sustainability considerations, terminology, and sequencing of events. Moreover, the participants supported the argument that the research outcomes fill an existing gap in industry practice and could potentially offer better control over the collaborative SBD process. Following are two quotes that demonstrate the nature of the feedback received:

I like it [the model]. It is very useful, and I'll use it myself. ... It [SBD] is a complex process and the level of detail presented in the model is the most appropriate. You cannot represent it in a simpler way. (Mechanical Engineer, Energy Modeller)

It is very well done, very comprehensive. I can recognise the process; it seems to be the type of way we approach things. .... It is very useful because you can ensure that every step of design is considered, at least. (Sustainability Consultant, BIM Specialist)

Additionally, the participants believed that systematising workflow management, for SBD, could assist in achieving sustainability objectives in the most economical way possible in terms of time, cost, and effort. Therefore, the results of this study indicate the following as the main principles for SBD implementation: (i) clear definition of sustainability objectives before design delivery, (ii) frequent feasibility checks for sustainability goals and benchmarks, (iii) iterative process of building design and sustainability assessment, (iv) concurrent parallel tasks, and (v) clear rules with an amount of customisation for bespoke projects. It is believed that this can be achieved through the efficient use of technological enablers. Therefore, it is argued that a transparent, holistic, and comprehensive process can assist in improving coordination across multidisciplinary distributed teams so as to provide quality assurance for SBD. The research outcomes present a potential support to the development of a Digital Plan of Work (DPoW) for BIM-enabled SBD, which could standardise the creation of EIR (Employers Information Requirements) and BEP (BIM Execution Plans) for 
sustainability. It is infered that a common definition for multidisciplinary SBD can promote better collaboration by harnessing the intellectual inputs of stakeholders with varying areas of expertise. Furthermore, this detailed approach can assist in the development of more realistic front-loaded project programmes that consider existing UK Building Regulations (e.g. Part L) and sustainability certifications (e.g. BREEAM).

\section{Discussion and conclusion}

Systematising multidisciplinary SBD processes (utilising BIM) can improve multidisciplinary communication, and thus, assist in achieving sustainability objectives more efficiently. Hence, the main goal of this study was to investigate, model, and facilitate the BIM-enabled SBD process. The focus was on the improvement of multidisciplinary collaborative SBD management by developing a systematic approach for its planning and delivery. For this purpose, this study identified the patterns that currently exist during early collaborative SBD development, and coordinated them into a systematic process for BIM-enabled SBD implementation (Figure 3). To move from the spider-web communication architecture to a hub-centric one, the existing communication methods of the best practices were mapped utilising IDEF3 CE process modelling (Mayer et al., 1995). Twenty Narratives were analysed to identify the tasks, deliverables, and information requirements that occur during Concept Design (RIBA stage 2). In order to systematise communication during design development, soft-gates were identified for the critical decision points, and aligned with design criteria and benchmarks. Furthermore, the logical decisions and the commands of the IDEF process model were used as the Service layer of a workflow management system for BIM-enabled SBD delivery. The GBB workflow management concept enables transparency of the SBD process among team members, and prompts communication by clarifying responsibilities and interdependencies of tasks and deliverables. Automated asynchronous messages (e.g. notifications) are sent when actions need to be undertaken, or for informing the users regarding constraints, and progress (see Figure 5). By enabling multiple viewpoints and perspectives of a holistic SBD process, a wide range of stakeholders, with varying areas of expertise, are engaged efficiently. The following subsections summarise the lessons learnt during this research along with the implications of the project's outcomes for SBD implementation.

\section{Opportunities for improvement of SBD management utilising technological enablers}

An extensive literature review along with in-depth interviews with industry experts (stage 1) served to determine the current implementation methods of collaborative SBD. Subsequently, it is established that the existing technological enablers such as BIM, BPA, and ICT have proven benefits for managing the design process (DTI, 2007). For sustainability, though, their integration remains low due to the lack of a comprehensive process for BIM-enabled SBD implementation and delivery. In order to reach their potential, re-thinking of the existing collaboration processes is required (Garber, 2009). Therefore, to make a step change towards SBD, assisted by the new technological improvements (i.e. software, hardware, and networks), there is a need to specify the components and processes of BPA within BIM collaboration. The 
challenge that this incorporation faces is the coordination of all available elements, which are necessary to achieve optimum results (Ruikar et al., 2006). To do this, critical SBD decisions should be considered timely in order to assess trade-offs between design aspects that are delegated to disciplines with varying specialisations.

\section{Identification and definition of BIM-enabled SBD components}

During this study, the importance of incorporating several design disciplines from the early stages of SBD was affirmed (stages 1-4). This notion is widely acknowledged and documented in the literature (Bouchlaghem et al., 2005; Mills and Glass, 2009), while it is also stressed that early decisions are crucial in order to achieve sustainability in the resulting design outcome (Schlueter and Thesseling, 2009). It was found that ad-hoc processes that are currently followed, for organising SBD, fail to deliver the correct sustainability information that each role needs to perform their duties, during SBD implementation, resulting in increasing uncertainty to achieve sustainability goals. In order to enable (BIM) technologies to reach their full potential, the roles within the design team need to be clarified, along with their tasks and deliverables, so as to become meaningful and useful for multidisciplinary collaboration. For this reason, this research focused on defining the roles, responsibilities, and competencies, which are necessary for the implementation of SBD, along with their contributions during the early design stages.

\section{Rules-based coordination of SBD tasks and deliverables}

The IDEF process model, for BIM-enabled SBD, was developed through a series of inductive and deductive steps (abductive approach). In-depth semi-structured interviews, utilising the CDM (Klein et al.,1989), assisted in identifying the workflow patterns that took place during collaborative design of sustainable buildings, and reflect on their outcomes based on lessons learnt (successes and failures) of the best practices. It was inferred that traditional working processes cannot be employed to achieve complex high-performing buildings, and that a CE design process approach to SBD is essential. During the traditional building design process, each stakeholder passes fixed information to the next one, which results in compromised design outcomes. What the CE approach suggests, for SBD, is that design solutions are developed, assessed, and revised collaboratively, as design progresses. Therefore, a single linear prescribed process is not viable, for SBD, because the complexity, amount of specialisation and individual project needs do not permit the process to be defined without iterations. The proposed SBD process, developed in this research project, combines the sequential principles found in organisational design theory (task-oriented network) (Laseau, 2001) with the spiral metaphor (from abstract to concrete design concept) of the design process (Goldschmidt, 2014; Watts, 1966). Thus, this research aimed to improve BIM maturity level for SBD, assisting in the transition from " $a d$ hoc" to "defined", and then, to "managed" (Succar et al., 2012).

The importance of decision points has been stressed in PAS 1192-2:2013 (BSI, 2013) and BS EN ISO 19650-1:2018 (British Standards Institution, 2019) as a critical aspect of the BIM collaborative process. For 
this reason, this research identified the critical decision points, for $\mathrm{SBD}$, and aligned those with the appropriate sustainability considerations and criteria. The SBD decision points comprise two types of gates; hard-gates when the design freezes until the review is conducted, and soft-gates that allow the project to proceed in parallel, thus enabling a CE approach to SBD. It is suggested that the hard-gates serve the purpose of committing to decisions collectively. Additionally, soft-gates were identified throughout the process so that the decision making points occur in parallel. Instead of design participants working in isolated silos, between the hard-gates (start and end of Concept Design), soft-gates during the Work In Progress (WIP) phase (BSI, 2013b) can facilitate communication by triggering design tasks so as to clarify the process for SBD practitioners and reduce uncertainty.

It was derived that the contributions of a variety of expertise's roles, during SBD development, result in a front-loaded process (CURT, 2004). Furthermore, the findings show that the process can be mapped in a more detailed manner than the RIBA Plan of Work (2013). The collaborative patterns, at Concept Design stage, are found to be repeatable for a variety of different non-domestic building types such as education, healthcare, and offices (stages 2-3). This fact enabled the development of a systematic approach to SBD, based on CE principles (Love and Gunasekaran, 1997; Gunasekaran and Love, 1998). This approach would allow lessons learnt to be incorporated for the design of future buildings.

\section{Formal and informal communication in a centralised system}

The IDEF3 process model can be utilised within a CDE to facilitate the implementation of a collaborative SBD process for Concept Design. To analyse the delivery of BIM-enabled SBD, GBB conceptual workflow management prototype tool was developed. GBB made SBD goals, roles, responsibilities, methods, and deliverables explicit by coordinating them into a common process holistically. Its structure and schematics were demonstrated through Use Case Scenarios (Carroll, 1995) utilising Sequence Diagrams and the UML notation (OMG, 2011). It is suggested that the IDEF 3 model can act as the Service layer in a three-layer system design (Buschmann et al., 1996). As such, its role would be to coordinate the top (Presentation) and bottom (Data and Knowledge Access) layers by containing the logical decisions and the commands of the application.

GBB was developed to address the issue of informal and formal communication that emerged from the case studies' narratives (stage 3). Drawings, contractor's programmes, and other information represent formal communication, and day-to-day communication represents informal organisation. Inconsistencies between the two exist due to the lack of project team alignment for SBD. The interviewees described the role of the Sustainability Engineer as prominent, in the early design stages. However, their collaboration cannot be secured, with the current procurement methods, since in most cases their communication with the Architect occurs informally and is not recorded in the formal systems. Therefore, their contribution in the SBD process is severely underestimated. The findings show that the SBD process is iterative, and it is about assessing, revising, and re-assessing sustainability as design progresses. 


\section{Evaluation of research outcomes and implications for SBD practice}

There was consensus amongst participants regarding the usefulness and adequacy of the IDEF 3 process model for the implementation of collaborative SBD. The participants considered the research output to be very well-structured, clear, relevant, comprehensive, and easy to understand and navigate. Furthermore, they acknowledged its value as a guideline for considering the most critical aspects of SBD, and for communicating them among the design team for better alignment. Overall, the feedback was enthusiastic with the interviewees emphasising on the appropriateness of the sustainability considerations, terminology, and sequencing of events. Additionally, minor alterations to the process model were recommended for its refinement (stage 4). Moreover, the participants supported the argument that the research outcomes fill an existing gap in industry practice and could potentially offer better control over the SBD process. Finally, the participants believed that systematic workflow management, for SBD, could assist in achieving sustainability objectives in the most economical way possible in terms of time, cost, and effort. Therefore, the results of this study indicate the following as the main principles for SBD implementation: (i) clear definition of sustainability objectives before design delivery, (ii) frequent feasibility checks for sustainability goals and benchmarks, (iii) iterative process of building design and sustainability assessment, (iv) concurrent parallel tasks, and (v) clear rules with an amount of customisation for bespoke projects.

\section{Recommendations for future work}

The findings of this study could be the basis for further research in several areas. Further work is needed to establish whether the systematic process developed improves SBD implementation, and to better understand the extent to which it affects in achieving sustainability objectives. To actualise that, more modelling work needs to be conducted in order to determine the scope of tasks, and their requirements for BIM-enabled SBD, for the rest of the RIBA Plan of Work's 2013 stages. The process should also be tested through practical applications to real life projects to examine its long-term efficacy as well as reproducibility and dependability of the research outcomes (various building types, different locations). Therefore, additional work needs to be done (action research, usability and functionality testing) for the development of a functioning tool for the workflow management of BIM-enabled SBD. Further research needs to be undertaken in the following areas to improve BIM maturity for SBD: (i) integration with existing BIM and BPA tools along with automation of certain performance evaluation exercises; (ii) integration with existing collaboration platforms and project management tools; (iii) visualisation of day-to-day progress, with carefully consideration of privacy and permissions; and (iv) compliance checking towards regulations and reporting, including a scoring system for design criteria.

\section{Acknowledgements}

This work was supported by the Engineering and Physical Sciences Research Council (EPSRC) under Grant 1472558. The authors are thankful to the industry experts who agreed to participate in this study and shared valuable knowledge. 


\section{References}

Ansah, M.K., Chen, X., Yang, H., Lu, L. and Lam, P.T., (2019), “A review and outlook for integrated BIM application in green building assessment”, Sustainable Cities and Society, Vol. 48, p.101576.

Baker, S., and Edwards, R. (2012), How many qualitative interviews is enough, available at http://eprints.ncrm.ac.uk/2273

Barbour, R. S. (2001), "Checklists for improving rigour in qualitative research: a case of the tail wagging the dog?", British medical journal, Vol. 322 No. 7294, pp. 1115.

Bordens, K. S. and Abbott, B. B. (2002), Research design and methods: A process approach, McGraw-Hill. Bouchlaghem, D. (2012), Collaborative Working in Construction, 2 Park Square, Milton Park, Abingdon, Oxon OX14 4RN: Taylor \& Francis.

Bouchlaghem, D. et al. (2005), "ICT-enabled collaborative working environment for concurrent conceptual design”, Architectural Engineering and Design Management. Taylor \& Francis, Vol. 1 No. 4, pp. 261-280.

Bowen, G. A. (2008), "Naturalistic inquiry and the saturation concept: a research note", Qualitative research, Vol. 8 No. 1, pp. 137-152.

Brahme, R. et al. (2001), "Complex building performance analysis in the early stages of design", in Seventh International IBPSA Conference, pp. 661-668.

BREEAM (2014), BREEAM UK New Construction, Non-Domestic Buildings, Technical Manual, SD5076: 0.1 (draft) 2014. Watford, UK: BRE Global Ltd.

British Standards Institution (2019), BS EN ISO 19650-1:2018 Organization and digitization of information about buildings and civil engineering works, including building information modelling (BIM). Information management using building information modelling. Concepts and principles.

BSI (2013), PAS 1192-2:2013 - Specification for information management for the capital/delivery phase of construction projects using building information modelling, available at: http://shop.bsigroup.com/Navigateby/PAS/PAS-1192-22013/: CIC.

Buschmann, F. et al. (1996), Pattern-Oriented Software Architecture Volume 1: A System of Patterns, John Wiley \& Sons Ltd.

Carroll, J. M. (1995), “Introduction: the scenario perspective on system development", Scenario-Based Design: Envisioning Work and Technology in System Development, Ed Caroll, JM, pp. 1-17.

Cinquemani, V. and Prior, J. J. (2010), Integrating BREEAM throughout the design process: a guide to achieving higher BREEAM and code for sustainable homes ratings through incorporation with the RIBA outline plan of work and other procurement routes, Bracknell: IHS/BRE Press. 
Coyne, I. T. (1997), "Sampling in qualitative research. Purposeful and theoretical sampling; merging or clear boundaries?", Journal of advanced nursing, Vol. 26 No. 3, pp. 623-630.

Crawley, D. and Aho, I. (1999), "Building environmental assessment methods: applications and development trends", Building Research \& Information. Taylor \& Francis, Vol. 27 No. 4-5, pp. 300-308.

CURT (2004), Collaboration, Integrated Information, and the Project Lifecycle in Building Design,

Construction and Operation, available at: http://codebim.com/wp-

content/uploads/2013/06/CurtCollaboration.pdf (accessed: 13 October 2015).

Davies, D., and Dodd, J. (2002), "Qualitative research and the question of rigor", Qualitative health research, Vol. 12 No. 2, pp. 279-289.

Ding, L., Zhou, Y. and Akinci, B. (2014), "Building Information Modeling (BIM) application framework: The process of expanding from 3D to computable nD”, Automation in Construction. Elsevier, Vol. 46, pp. 82-93.

Drongelen, I. K. (2001), “The iterative theory-building process: rationale, principles and evaluation”, Management Decision, available at: http://www.emeraldinsight.com/doi/abs/10.1108/EUM0000000005799 DTI (2007), Avanti - Report from The Construction Research Programme - Project Showcase, available at: http://www.cpic.org.uk/publications/avanti/.

Edwards, R.E., Lou, E., Bataw, A., Kamaruzzaman, S.N. and Johnson, C., (2019), "Sustainability-led design: Feasibility of incorporating whole-life cycle energy assessment into BIM for refurbishment projects", Journal of Building Engineering, Vol. 24, p.100697.

Egan, J. (1998), Rethinking construction. Department of Environment, Transport and the Region.

El-Diraby, T., Krijnen, T. and Papagelis, M., (2017), "BIM-based collaborative design and socio-technical analytics of green buildings", Automation in Construction, Vol. 82, pp.59-74.

Farmer, M. (2016), The Farmer Review of the UK Construction Labour Model.

Garber, R. (2009), "Optimisation Stories: The Impact of Building Information Modelling on Contemporary Design Practice", Architectural Design, Wiley Online Library, Vol. 79 No. 2, pp. 6-13.

Glaser, B. G. (1978), Theoretical sensitivity: Advances in the methodology of grounded theory, Sociology Pr. Goldschmidt, G. (2014), Linkography: Unfolding the Design Process, Cambridge, Massachusetts; London: The MIT Press.

Green Building Education Services (2011), LEED Study Guide.

Gunasekaran, A. and Love, P. E. D. (1998), “Concurrent engineering: a multi-disciplinary approach for construction”, Logistics Information Management, MCB UP Ltd, 11(5), pp. 295-300. 
HM Government (2018), Construction Sector Deal, available at:

https://www.gov.uk/government/publications/construction-sector-deal.

Jaewook Lee, Hyuncheul Yang, Jinkang Lim, Taehoon Hong, Jimin Kim \& Kwangbok Jeong (2020), “BIMbased preliminary estimation method considering the life cycle cost for decision-making in the early design phase", Journal of Asian Architecture and Building Engineering, DOI: 10.1080/13467581.2020.1748635

Jalaei, F., Jalaei, F. and Mohammadi, S., (2020), “An integrated BIM-LEED application to automate sustainable design assessment framework at the conceptual stage of building projects", Sustainable Cities and Society, Vol. 53, p.101979.

Kagioglou, M. et al. (1998), "Final report: Generic design and construction process protocol”, University of Salford, Salford.

Klein, G. A., Calderwood, R. and Macgregor, D. (1989), "Critical decision method for eliciting knowledge", IEEE Transactions on Systems, Man and Cybernetics, IEEE, 19(3), pp. 462-472.

Laseau, P. (2001), Graphic Thinking for Architects \& Designers, John Wiley \& Sons.

Latham, S. M. (1994), Constructing the team, HM Stationery Office.

Levin-Rozalis, M. (2004), "Searching for the unknowable: A process of detection-Abductive research generated by projective techniques", International Journal of Qualitative Methods, Vol. 3 No. 1, pp. 1-18.

Lewis, K. and Mistree, F. (1998), "Collaborative, sequential, and isolated decisions in design", Journal of Mechanical Design. American Society of Mechanical Engineers, Vol. 120 No. 4, pp. 643-652.

Lloyd, P. (2017), "From Design Methods to Future-Focused Thinking: 50 years of design research", Design Studies. Elsevier Ltd, 48, pp. A1-A8.

Love, P. E. D. and Gunasekaran, A. (1997), "Concurrent engineering in the construction industry”, Concurrent Engineering, SAGE Publications, Vol. 5 No. 2, pp. 155-162.

Lützkendorf, T. and Lorenz, D. P. (2006), "Using an integrated performance approach in building assessment tools", Building Research \& Information, Taylor \& Francis, Vol. 34 No. 4, pp. 334-356.

Marzouk, M. and Enaba, M. (2019), "Analyzing project data in BIM with descriptive analytics to improve project performance", Built Environment Project and Asset Management, Vol. 9 No. 4, pp. 476-488.

Mayer, R. J. (1992), IDEF Family of Methods for Concurrent Engineering and Business Re-engineering Applications, College Station, Texas, USA.

Mayer, R. J. et al. (1995), Information Integration for Concurrent Engineering (IICE) - IDEF3 process description capture method report, DTIC Document.

Mendler, S. and Odell, W. (2000), The HOK guidebook to sustainable design, John Wiley \& Sons. 
Meredith, J. (1993), "Theory building through conceptual methods", Journal of Operations \& Production Management, available at: http://www.emeraldinsight.com/doi/pdf/10.1108/01443579310028120

Messner, J., Anumba, C., Dubler, C., Goodman, S., Kasprzak, C., Kreider, R., Leicht, R., Saluja, C., and Zikic, N. (2019), BIM Project Execution Planning Guide, Version 2.2. Computer Integrated Construction Research Program, The Pennsylvania State University, University Park, PA, USA, August, available at http://bim.psu.edu.

Microsoft (2015), Three-Layered Services Application, available at: https://msdn.microsoft.com/enus/library/ff648105(d=printer).aspx (accessed: 18 November 2015).

OMG (2011), UML 2.4.1 Superstructure Specification, August, DOI: formal/2011-08-06.

Pala, M. and Bouchlaghem, N. M. (2012), How could ICT benefit design managers for assessing sustainability of their project?, Escola Politécnica, University of São Paulo, Brazil and the Centre for Innovative \& Collaborative Construction Engineering, Loughborough University, UK.

Patton, M. Q. (1990), Qualitative evaluation and research methods, SAGE Publications, Inc.

Potts, C. and Bruns, G. (1988), "Recording the reasons for design decisions", in Proceedings of the 10th international conference on Software engineering, IEEE Computer Society Press, pp. 418-427.

Reichertz, J. (2004), 4.3 Abduction, deduction and induction in qualitative research, Available at: https://pdfs.semanticscholar.org/749f/cb02c73b6a5a54fbda02583d154716baba89.pdf

Reigeluth, C. M. (1999), “The elaboration theory: Guidance for scope and sequence decisions”, Instructional design theories and models: A new paradigm of instructional theory, Vol. 2, pp. 425-453.

RIBA (2013), RIBA Plan of Work 2013. RIBA. Available at: http://www.ribaplanofwork.com/ RIBA Enterprises Ltd (2019), NBS National BIM Report 2019, available at: https://www.thenbs.com/knowledge/national-bim-report-2019

Ritchie, J., Lewis, J., Nicholls, C. M., and Ormston, R. (Eds.) (2013), Qualitative research practice: A guide for social science students and researchers, SAGE.

Robichaud, L. B. and Anantatmula, V. S. (2010), "Greening project management practices for sustainable construction", Journal of Management in Engineering, American Society of Civil Engineers, Vol. 27 No. 1, pp. $48-57$.

Ruikar, K., Anumba, C. J. and Carrillo, P. M. (2006), "VERDICT - An e-readiness assessment application for construction companies", Automation in Construction, Elsevier, Vol. 15 No. 1, pp. 98-110. 
Santos Rú, Aguiar Costa Antó, Silvestre JoséD, Pyl L. (2020), "Development of a BIM-based Environmental and Economic Life Cycle Assessment tool”, Journal of Cleaner Production, https://doi.org/10.1016/j.jclepro.2020.121705

Schlueter, A. and Thesseling, F. (2009), "Building information model based energy/exergy performance assessment in early design stages", Automation in Construction, Elsevier, Vol.18 No. 2, pp. 153-163.

Shelbourn, M. et al. (2007), "Planning and implementation of effective collaboration in construction projects", Construction Innovation. Emerald Group Publishing Limited, Vol. 7 No. 4, pp. 357-377.

Sinclair, D. (2013) Assembling a Collaborative Project Team: Practical tools including Multidisciplinary Schedules of Services. RIBA Publishing.

Succar, B., Sher, W. and Williams, A. (2012), "Measuring BIM performance: Five metrics”, Architectural Engineering and Design Management, Vol. 8 No. 2, pp. 120-142.

Svennevig, J. (2001), “Abduction as a methodological approach to the study of spoken interaction”, Norskrift, Vol. 103, pp. 1-22.

UK Green Building Council (2019), Net Zero Carbon Buildings: A Framework Definition, available at: https://www.ukgbc.org/ukgbc-work/net-zero-carbon-buildings-a-framework-definition/.

Uschold, M. and Gruninger, M. (1996), “Ontologies: Principles, methods and applications”, The Knowledge Engineering Review, 11(2), pp. 93-136.

Watts, R. D. (1966), “The elements of design”, The design method, Springer, pp. 85-95.

Wilkinson, P. (2005), Construction collaboration technologies: the extranet evolution, London; New York: Taylor \& Francis.

Wolstenholme, A. et al. (2009), Never waste a good crisis: A review of Progress since Rethinking Construction and Thoughts for Our Future, Constructing Excellence.

Wong, K. A. and Fan, Q. (2013), "Building information modelling (BIM) for sustainable building design", Facilities, Emerald Group Publishing Limited, Vol. 31 No. 3/4, pp. 138-157.

Yang, R. J., Zou, P. X. W. and Keating, B. (2013), “Analysing stakeholder-associated risks in green buildings: a social network analysis method", WBC 2013: Proceedings of the 19th International CIB World Building Congress, Queensland University of Technology, pp. 1-12.

Zanni, M. A., Soetanto, R. and Ruikar, K. (2017), “Towards a BIM-enabled sustainable building design process: roles, responsibilities, and requirements", Architectural Engineering and Design Management, Taylor \& Francis, Vol. 13 No. 2, pp. 101-129. 